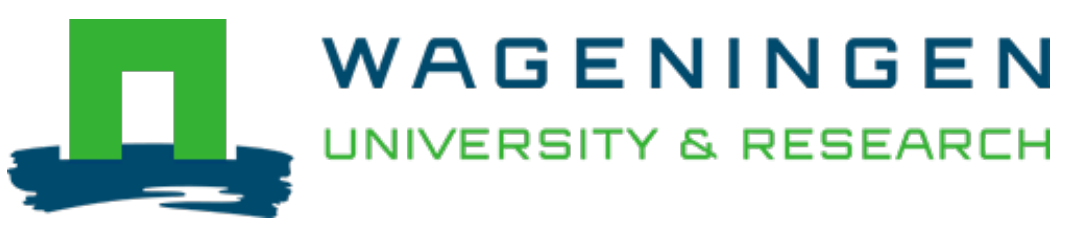

\title{
Assessment of fermentation as a household technology for improving food safety: a joint $\mathrm{FAO} / \mathrm{WHO}$ workshop.
}

\author{
Food Control \\ Nout, M.J.R.; Motarjemi, Y. \\ https://doi.org/10.1016/S0956-7135(97)00021-2
}

This publication is made publicly available in the institutional repository of Wageningen University and Research, under the terms of article $25 \mathrm{fa}$ of the Dutch Copyright Act, also known as the Amendment Taverne. This has been done with explicit consent by the author.

Article 25 fa states that the author of a short scientific work funded either wholly or partially by Dutch public funds is entitled to make that work publicly available for no consideration following a reasonable period of time after the work was first published, provided that clear reference is made to the source of the first publication of the work.

This publication is distributed under The Association of Universities in the Netherlands (VSNU) 'Article $25 \mathrm{fa}$ implementation' project. In this project research outputs of researchers employed by Dutch Universities that comply with the legal requirements of Article $25 \mathrm{fa}$ of the Dutch Copyright Act are distributed online and free of cost or other barriers in institutional repositories. Research outputs are distributed six months after their first online publication in the original published version and with proper attribution to the source of the original publication.

You are permitted to download and use the publication for personal purposes. All rights remain with the author(s) and / or copyright owner(s) of this work. Any use of the publication or parts of it other than authorised under article $25 \mathrm{fa}$ of the Dutch Copyright act is prohibited. Wageningen University \& Research and the author(s) of this publication shall not be held responsible or liable for any damages resulting from your (re)use of this publication.

For questions regarding the public availability of this publication please contact openscience.library@wur.nl 


\title{
Assessment of fermentation as a household technology for improving food safety: a joint FAO/WHO workshop*
}

\author{
M. J. R. Nout ${ }^{\dagger \S}$ and Y. Motarjemi ${ }^{\ddagger}$ (On behalf of all \\ workshop participants) ${ }^{\pi}$
}

Food safety and nutritional aspects of lactic acid fermentation processes for the purpose of complementary food preparation at household scale in tropical countries were assessed during an FAO/WHO workshop held in Pretoria, South Africa in December 1995.

Lactic acid fermentation was evaluated in particular, taking into consideration that microbial fermentation is only a part of the food preparation processes involving other operations such as soaking, cooking and the use of germinated cereals. The latter are of special interest as they enable the preparation of semiliquid porridges of high-nutrient density.

The present state of knowledge concerning the antimicrobial effects imparted by the acidity in lactic-fermented foods was reviewed, as well as the nutritional benefits of fermentation and use of germinated cereals. Areas requiring further research were identified and prioritized.

It was concluded that high priority should be given to research on: the effect of lactic acid fermentation on viruses, parasites, some bacteria and mycotoxins; risk assessment using the HACCP approach, health education of food handlers and consumer perception of fermented foods; characterization and optimization of fermentation processes and development of appropriate starters; and some physiological and nutritional effects of consumption of fermented foods. (C) 1997 Elsevier Science Ltd.

Keywords: lactic fermentation; foodborne diseases; diarrhoea; safety; pathogens; virus; parasite; bacteria

\footnotetext{
'Department of Food Science, Agricultural University, Bomenweg 2, 6703 HD Wageningen, The Netherlands. 'Food Safety Unit, World Health Organization, CH-1211 Geneva, 27 Switzerland. *This publication is based on the report of a WHO Workshop (Fermentation: Assessment and Research, unpublished document WHO/FNU/FOS/96.1, single copies of which are available upon request from Food Safety Unit, World Health Organization, 1211 Geneva 27, Switzerland). "To whom correspondence should be addressed (fax +31 317 484893; e-mail: rob.nout@algemeen.lenm.wau.nl). 'Participants in the Workshop were Martin Adams, Leoni Bosman, Richard Fuchs, Dave Harcourt, John W. Hastings, Wilhelm H. Holzapfel, Alex von Holy, Gabriel Kouthon (Co-Secretary), Cherl-Ho Lee, Brenda Liebenberg, Ilze Meyer, Wilbald Lorri, Joan Matji, Lilian Marovatsanga, S.K. Mbugua, Patience Mensah, Zahara Merican, Yasmine Motarjemi (Co-Secretary), M.J. Robert Nout (Rapporteur), Olusola B. Oyewole (Chairman), Fernando Quevedo (Vice-Chairman), Alan Reilly, F.W.J. van Rijssen, Theo van de Sande, Morenike O. Sanni, Keith H. Steinkraus, Ulf Svanberg, Andrew Tomkins, Jocelyn Webster, Andrew Westby, Johan de Wet, Ina Willken.
} 


\section{INTRODUCTION}

Annually, some 1500 million episodes of diarrhoea occur worldwide in children under the age of five, and over 3 million children die as a direct result. Indirectly diarrhoeal diseases kill many more children as they are one of the underlying major causes of malnutrition. It is estimated that up to $70 \%$ of these diseases are of foodborne origin and are caused by contaminated food and drinking water (Motarjemi $e t$ al., 1993). Diarrhoeal diseases are a major health problem, particularly in developing countries. Raw foods are frequently the source of contaminants, as some foods may naturally harbour pathogens or derive from infected animals. During handling and preparation food contamination may occur through diverse sources including nightsoil, polluted water, food handlers (e.g. soiled hands), flies and pests, domestic animals, dirty utensils, dirt, or human and animal excreta in the environment. Moreover, during food preparation there is the added risk of crosscontamination. But, epidemiological studies have shown that one of the major causes of foodborne diseases worldwide is time-temperature abuse during food preparation, leading to survival and/or growth of pathogens - or production of toxin - to diseasecausing levels (Fig. 1). Usually two types of practice lead to time-temperature abuse: (a) storage of prepared food at temperatures that favour growth of pathogenic bacteria and/or formation of toxins; and (b) insufficient cooking or reheating of food prior to consumption.

The education of food handlers, particularly mothers and caretakers of small children, to avoid these errors is essential for the prevention of foodborne diseases. Observing the basic principles of food hygiene, including (i) thorough cooking, (ii) proper

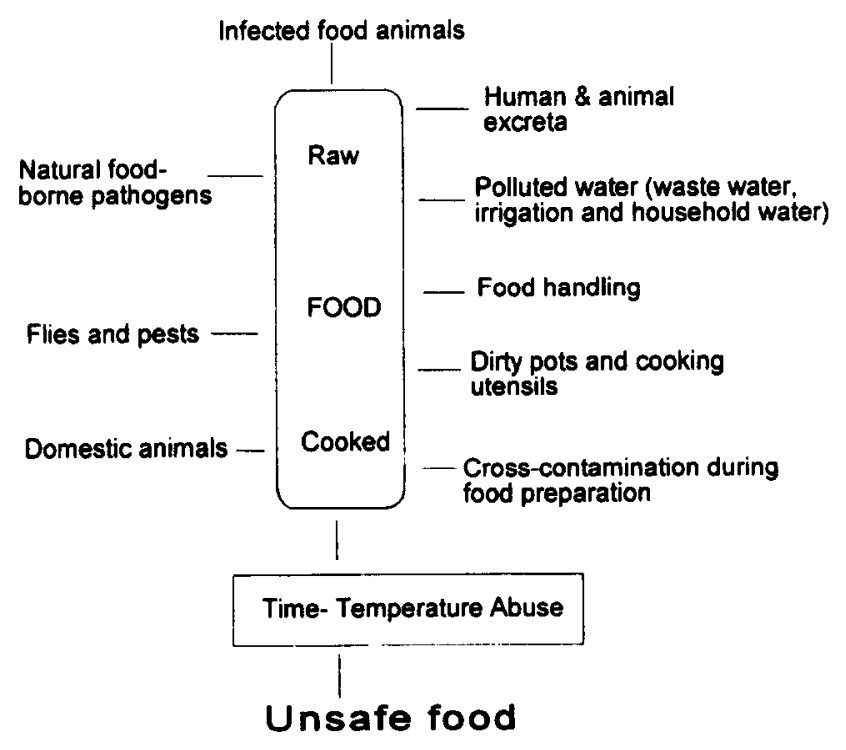

Figure 1 Sources of food contamination storage and (iii) thorough reheating of stored food, would prevent many cases of foodborne diarrhoea (Motarjemi et al., 1994).

In practice, lack of facilities for cold storage (e.g. refrigerators) or fuel for hot holding, thorough cooking and reheating (Motarjemi et al., 1993) limit the implementation of these principles of hygiene, and increase the risk of foodborne disease.

Various fermentations have been used traditionally and worldwide to prepare and preserve food. In some African countries in particular, it is customary to give infants lactic acid-fermented cereal products such as ogi (Nigeria), or uji (United Republic of Tanzania, Uganda, Kenya). In view of the limitations mentioned above, scientists and public health authorities have considered that lactic acid fermentation might be an alternative technology to safeguard food, when cold and hot storage is not feasible. It has also been suggested that lactic acid-fermented products can be consumed without reheating and that this would make it possible to partly overcome the problem of shortage of fuel.

In addition to improving safety, some nutritional benefits have also been attributed to fermented foods, and therefore they have been promoted for nutritional purposes (Nout, 1993).

However, several questions arise when considering the application of fermentation at the household level. Firstly, what kind of hazard can be controlled by the application of this technology? And what risks are associated with the actual application of the technology due to a food handler's lack of knowledge, to the local choice of ingredients and recipes or to the poor hygienic food preparation conditions? Past experience has shown that sometimes fermented foods have been implicated with foodborne illnesses (Nout, 1994). Thirdly, what considerations of a sociocultural nature should be taken into account in order to successfully apply fermentation technology, transfer it to another region, or to promote it? And finally, weighing the risks and benefits, should such a technology be promoted to prevent foodborne diarrhoea or to improve the nutritional value of foods?

With these considerations in mind, the Food and Agriculture Organization of the United Nations and the World Health Organization organized a Workshop, in collaboration with the Department of Health of the Republic of South Africa, to assess lactic acid fermentation as a household technology for improving food safety (Pretoria, 11-15 December 1995).

The objectives of the Workshop (FAO/WHO, 1996) were to review the current state of the art with respect to benefits and risks of fermentation, giving particular consideration to African complementary foods; to develop practical interventions for improving the safety and nutritional quality of fermented foods; and to review gaps in knowledge and establish where additional research is needed. 
Selected background papers delivered during the Workshop are collected in this issue of Food Control.

\section{FERMENTATION}

Fermentation can be described as a desirable process of biochemical modification of primary food products brought about by microorganisms and their enzymes. Fermentation is carried out to enhance taste, aroma, shelf-life, texture, nutritional value and other attractive properties of food. It is often part of a sequence of process operations including one or more of the following: cleaning, grinding, soaking, cooking, packaging and distribution.

It is carried out in many parts of the world, with regional differences depending on the availability of raw materials, consumption habits, time to carry out laborious processes, and social patterns. Fermented foods intended for infants and young children are mainly lactic-fermented cereals (maize, sorghum, millet), root crops (e.g. cassava), milk and, to a lesser extent, fish, meat and vegetables.

Lactic acid fermentation is a natural process that is brought about by the lactic acid bacteria present in the raw food, or those derived from a starter culture. At the household level, a variety of techniques are used in Africa. For example, cereal grains, after cleaning, are soaked in water for a few days during which a succession of naturally occurring microorganisms will result in a population dominated by lactic acid bacteria. In such fermentations endogenous grain amylases generate fermentable sugars that serve as a source of energy for the lactic acid bacteria. The fermentation process can be accelerated by adding a starter culture of lactic acid bacteria, for instance by adding some already fermented material (a practice referred to as back-slopping). In some lactic acidfermented cereal products such as togwa, germinated millet or sorghum grains are used as a source of amylase and/or starter culture. At present, industrially produced starter cultures are used in Africa, but mainly in the fermentation of dairy products (Wangoh et al., 1992).

\section{BENEFITS AND RISKS ASSOCIATED WITH LACTIC ACID FERMENTATION}

Fermentation is often just one step in the process of fermented food preparation. Other operations such as size reduction, salting or heating also affect final product properties. Therefore, where a process effect is observed it may have been caused by other unit operations or by a combination of other operations with fermentation rather than by the fermentation step itself. The following section presents the risks and benefits associated with the fermentation step only.

\section{Biological agents}

Lactic acid fermentation inhibits growth, survival and toxin production of a number of pathogenic bacteria. The extent to which bacteria are inhibited will depend on the organism concerned, the temperature, the amount of undissociated acid produced and the properties of the food, i.e. its buffering capacity. In cereal and vegetable products which are weakly buffered, an efficient lactic acid fermentation will produce a $\mathrm{pH}$ of 4 or less, at which the growth of bacterial pathogens is inhibited and many bacteria will die at a rate which increases with increasing ambient temperatures.

The potential of lactic acid fermentation for controlling food contamination depends on factors that are often difficult to quantify, such as initial level of contamination, levels of hygiene and sanitation, which in turn depend on local conditions, and on the degree of acidification. It should be noted that fermentation cannot replace the need for observing rules of food hygiene, and minimizing the risk of contamination. This is particularly important since some pathogens may be acid resistant and may survive the fermentation process: foodborne viruses such as rotavirus which is a common cause of childhood diarrhoea have shown to be relatively acid resistant; there are also emerging patterns of acid resistance in some enteropathogens such as $E$. coli O157:H7. Further research is also needed to determine the effect of acidity on the survival and infectivity of parasites such as Cryptosporidium spp., Giardia lamblia and foodborne trematodes, since the cysts of these organisms often show resistance to adverse conditions.

\section{Chemical substances}

Lactic acid fermentations have been associated with the reduction of certain naturally occurring toxins in plant foods. For example, levels of cyanide from cassava are reduced in several traditional fermented products, although the reduction in the cyanide level may be principally the consequence of endogenous enzymes rather than microbial activity. However, the microorganisms may play a role in softening the plant tissue, thus indirectly facilitating the reduction in cyanide.

There are also toxins produced by moulds (mycotoxins) and bacteria (enterotoxins, botulinum toxin). The role of fermentation in reducing mycotoxins in food shows contradictory results. In addition, there is no evidence to suggest that the fermentation step will reduce the level of preformed bacterial toxins. Therefore, fermentation should not be expected to reduce the level of mould or bacterial toxins in food.

\section{Physical matter}

Fermentation itself cannot reduce the level of contamination with extraneous matter, but other 
operations that precede fermentation, e.g. washing, may contribute to removal of dirt.

\section{Nutritional impact}

Fermentation can have multiple effects on the nutritional value of food. Microbial fermentation leads to a decrease in the level of carbohydrates as well as some non-digestible poly- and oligosaccharides. The latter reduces side effects such as abdominal distention and flatulence. Certain amino acids may be synthesized, and the availability of $\mathbf{B}$ group vitamins may be improved. Fermentation techniques which involve a combination of amylase-rich flour (ARF or power flour) and a lactic acid starter culture provide considerable opportunity for increase in nutricnt density. The decrease in viscosity of cooked starchy porridges by ARF enables the addition of more dry matter while maintaining a semi-liquid consistency.

Fermentation also provides optimum $\mathrm{pH}$ conditions for enzymic degradation of phytate which is present in cereals in the form of complexes with polyvalent cations such as iron, zinc, calcium, magnesium and proteins. This degradation occurs during the soaking of the grains in water which extends for $12-14 \mathrm{~h}$. Such a reduction in phytate may increase the amount of soluble iron, zinc and calcium several fold.

Tannin levels may be reduced as a result of lactic acid fermentation, leading to increased absorption of iron, except in some high tannin cereals, where little or no improvement in iron availability has been observed.

There are also indications of the presence of ironpromoting factors in fermented vegetables which would facilitate the absorption of iron in a phytaterich diet. An example of such a promoter is Vitamin $\mathrm{C}$ which is also better preserved in lactic acidfermented vegetables, compared with those processed by alternative methods.

On the other hand, protease inhibitors and the toxic effects of lectins are hardly affected by lactic acid fermentation. Microbially produced lactic acid can be a mixture of the optical isomers $\mathrm{L}-(+)$ and $\mathrm{D}-(-)$ lactic acid. The latter cannot be metabolized by humans and excessive intake can result in acidosis, i.e. a disturbance of the acid-alkali balance in the blood. The potential toxicity of $\mathrm{D}-(-)$ lactic acid for malnourished and sick children is of concern and further research is needed with regard to the $D-(-)$ lactic acid content of lactic acid-fermented foods prepared at the household level.

\section{IMPROVING SAFETY AND NUTRITIONAL VALUE}

Assessing the safety and nutritional value of fermented foods, and determining the intervention needed to improve their safety or nutritional quality should be considered in the context of the entire process, from the raw material to the end product. Considering present practices in the preparation of fermented complementary foods, three type of constraints or shortcomings were recognized.

(1) Lack of time and awareness of hygiene: lack of time may have significant implications regarding safety and nutritional quality of fermented foods because any time saved by cutting down on fermentation may jeopardize the effectiveness of acidification by lactic acid bacteria, or the enzymic degradation of chemical substances. A more time-efficient process may be achieved by using starter cultures, or by different distribution of labour, e.g. foods may be produced by an entrepreneur. Unjustified short-cuts that will make the food unsafe must be avoided. Improvement of product quality and safety could be achieved by applying principles of Good Manufacturing Practice and Good Hygienic Practice, and by using the Hazard Analysis Critical Control Point system (HACCP). HACCP is a food safety assurance tool used for identification, assessment and control of hazards throughout the process, from raw material to packaging and consumption. Application of HACCP to several fermented African foods, (uji, togwa and gari) was carried out during the Workshop to illustrate the use of this approach for identifying necessary measures for improving safety of fermented foods as well as for determining practices/behaviours which should be the subject of health education of food handlcrs. Application of the HACCP system also demonstrated the relatively high risks associated with the preparation of togwa, and the importance of assessing the safety of each product and each preparation individually (FAO/WHO, 1996).

(2) Deficient availability of nutrients: from a nutritional point of view it is possible to improve the nutrient density of foods while maintaining a semiliquid consistency by addition of ARF, provided that the starchy cereal or root crop is cooked. Likewise, it is possible to improve the protein content of porridges by enriching them with legumes, e.g. soybeans or cowpeas. These nutrition-oriented concepts have been successfully combined with that of lactic acid fermentation (Nout, 1993).

(3) Lack of status: a major social constraint which is associated with fermented foods for complementary purposes is that of poor image or low status when compared with industrial preparations which, in some countries, are considered superior and associated with progressiveness. In this regard, education of consumers and food handlers on the values of local produce is essential.

\section{RESEARCH NEEDS}

Much research on fermentation is carried out throughout the world. During the Workshop, current knowledge particularly relevant to the needs of 
developing countries, as well as the level of understanding on the potential and effects of the use of fermentation for prevention of foodborne diarrhoea and improving nutritional status, were assessed. Research areas were identified and prioritized that will increase the understanding of the scientific community with respect to safety, nutritional value, socio-economic and cultural aspects.

Some of the research areas worthy of high priority, as recommended by the Workshop, are:

- Effect of lactic acid fermentation on parasites, viruses and sub-lethally injured pathogenic bacteria, as well as acid-resistant bacteria;

- Effect of lactic acid fermentation on mycotoxins and the toxicity of their degradation products;

- Investigation of the role of individual processing steps and combination of steps in ensuring food safety (application of HACCP system);

- Assessing the risks associated with the household preparation of fermented complementary foods and identification of critical control points in the processing which should be the subject of health education of food handlers;

- Understanding the perception of consumers/food handlers, and determining appropriate mechanisms for their education;

- Characterization and optimization of complete lactic acid fermentation processes for adequate acidification;

- Only where appropriate, development of starter cultures for lactic acid fermentation;

- Mechanism and effect of consumption of fermented foods on the incidence of diarrhoea;

- Investigation into the significance of $D-(-)$ lactate acidosis associated with consumption of fermented foods;

- Effect of fermentation on the bioavailability of nutrients, especially iron, zinc, calcium and protein.

\section{CONCLUSION}

Thorough cooking of food is the single most effective way of controlling microbial hazards. On its own, lactic acid fermentation cannot eliminate all foodrelated health risks, hence fermentation should not be seen as a replacement for the need for observing the basic rules of food hygiene.

However, lactic acid fermentation, particularly when combined with other processing techniques, can contribute towards the safety, nutritional value, shelflife and acceptability of foods. From the food safety point of view the benefits include inhibition of most pathogenic bacteria growth and of bacterial toxin formation. Where facilities for refrigerated or hot holding are not available, lactic acid fermentation provides an affordable method to keep food safe until the next meal, provided that rapid and adequate acidification has been achieved. As a bonus, nutritional benefits (degradation of anti-nutritional factors and increased mineral bio-availability, improvement of protein digestibility of tannin-rich cereals, and degradation of flatulence-causing oligosaccharides) may result. Reduction of viscosity of starchy porridges is achieved by addition of germinated cereal grains; this enables the preparation of porridges of increased nutrient density that are still sufficiently liquid to be swallowed by infants. Moreover, lactic acid fermentation enhances the sensory properties of food leading to a variety of tastes.

High priority research areas were determined for obtaining a better understanding of the potential of this technology to contribute to health. These will be for the consideration of policy makers, food scientists and food technologists.

While the potential advantages of the fermentation technology, particularly when associated with other operations, were recognized, uncritical reliance on its beneficial effects is a matter of concern, particularly considering that acidification is mostly not monitored at the household level and that unsanitary conditions may result in considerable post-processing contaminations.

It was therefore recommended that in communities where lactic acid fermentation is usually carried out, this practice should be encouraged, and food handlers should be educated, in line with the HACCP approach, in identifying the critical control points of the process for controlling the safety of the products (FAO/WHO, 1996). Existing socio-economic and cultural relations and patterns should be examined, and the type of support which is needed to improve the safety and nutritional value of the fermented foods should be identified. Appropriate communication strategies and means should be developed and applied to inform households about appropriate fermentation techniques.

Where lactic acid fermentation is not known or used, a socio-cultural assessment should first be made of the appropriateness and feasibility of the fermentation practice in that community and its safety and nutrition implications, prior to any attempt to formally introduce fermentation technology. Multidisciplinary and collaborative research is essential for improving knowledge in this technology and its use for health purposes.

Coordination of research and exchange of data, for instance through a network of scientists working on this subject (a 'fermentation network'), would ensure methodical and steady progress towards reaching the set objectives.

\section{REFERENCES}

FAO/WHO (1996) Report of the FAO/WHO Workshop on assessment of fermentation as a household technology for 
improving food safety. Unpublished WHO document WHO/FNU/FOS/96.1, World Health Organization, Geneva

Motarjemi, Y., Käferstein, F., Moy, G. and Quevedo, F. (1993) Contaminated weaning food: a major risk factor for diarrhoea and associated malnutrition. Bulletin of the World Health Organization 71(1), 79-92

Motarjemi, Y., Käferstein, F., Moy, G. and Quevedo, F. (1994) Contaminated food, a hazard for the very young. World Health Forum 15(1), 69-72
Nout, M.J.R. (1993) Processed weaning foods for tropical climates. International Journal of Food Sciences and Nutrition 43, 213-221

Nout, M.J.R. (1994) Fermented foods and food safety. Food Research International 27, 291-298

Wangoh, J., Schulthess, W. and Struebi, P. (1992) Flavouring of the cultured milk product mala with fruits available in Kenya. Milchwissenschaft 47(1), 27-31 